\title{
Hydrological controls on sulfur cycling in the Green River formation
}

\author{
A. CRÉMIÈRE ${ }^{1 *}$, X. CUI ${ }^{2}$, C. TINO ${ }^{3}$, M. POMMER $^{4}$, M.

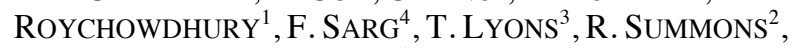 \\ A. SESSIONS ${ }^{1}$, J. AdKINS $^{1}$ \\ ${ }^{1}$ Division of Geological and Planetary Sciences, California \\ Institute of Technology, Pasadena, CA, USA \\ ("correspondence: cremiere@ caltech.edu) \\ ${ }^{2}$ Department of Earth, Atmospheric and Planetary Sciences, \\ Massachusetts Institute of Technology, Cambridge, \\ Massachusetts 02139, USA \\ ${ }^{3}$ Department of Earth and Planetary Sciences, University of \\ California, Riverside, CA, USA \\ ${ }^{4}$ Department of Geology and Geological Engineering \\ Colorado School of Mines, Golden, CO, USA
}

Unlike the ocean, we have limited understanding of how lacustrine sulfur cycling may have evolved with climate and basin evolution. Here, we measured the sulfur isotope compositions of pyrite, organic sulfur and carbonateassociated sulfate and molecular proxies in early Eocene sedimentary rocks from the Green River Formation, reflecting a period of high atmospheric $\mathrm{CO}_{2}$ levels and climate instability. Evolution of the terminal Uinta lake basin spanned from a shallow brackish environment to a hypersaline stratified lake. As the lake expanded and salinity rose, depositional cycles are marked by an increasing abundance of organic-rich rather than organic-lean carbonate mudrocks. We find that the deposition of organic-rich sediments seems to be associated with increasing fluvial inputs, a highly stratified water column, weakly euxinic photic zone, and enhanced burial of pyrite and sulfurized organic matter. Consistent with a previous study [1], paired pyrite and organic sulfur $\delta^{34} S$ values converge during those periods of freshwater stratification most likely due to a large fraction of the sulfate reservoir being consummed. Moreover, we observe a $\sim 30 \%$ positive shift in the sulfur isotope composition of all Sbearing sedimentary phases during the rising lake stage that cannot be easily reconciled with change in the source of sulfate. We speculate that this enrichment was caused by loss of ${ }^{34} \mathrm{~S}$-depleted $\mathrm{H}_{2} \mathrm{~S}$ (degassing) from the lake perhaps associated with transcient water mixing episodes during more arid periods.

[1] Tuttle and Goldhaber (1993), GCA 57, 3023-3039. 